\title{
Corrosion Behavior of a Low-Carbon Steel in Simulated Marine Splash Zone
}

\author{
Huan-Huan Wang ${ }^{1} \cdot$ Min Du ${ }^{1}$
}

Received: 18 September 2016/Revised: 13 November 2016/Published online: 17 February 2017

(C) The Chinese Society for Metals and Springer-Verlag Berlin Heidelberg 2017

\begin{abstract}
Experiments were designed to simulate the corrosion of a low-carbon steel exposed to a marine splash zone. The composition and morphology of the rust were investigated using Raman spectroscopy, X-ray photoelectron spectroscopy, energy-dispersive spectrometry and scanning electron microscopy. Corrosion resistance of the rust films was demonstrated by the electrochemical impedance spectroscopy. The wettability of the steel surface was calculated from the data concerning the wetting degree and the conductivity. The results showed that, in the initial stage, the products of the outer rust layer were mainly made up of $\mathrm{Fe}$ (III) oxyhydroxide, while the main component of the inner rust layer was magnetite. With an increase in the corrosion time, the inner rust layer continuously turned into the outer rust layer. In addition, both rust layers became dense, thus playing a protective role with respect to matrix. The existence of the rust layer significantly prolonged the residence time of the seawater on the sample surface, a result that tends to improve the cathodic protection effect for steel structures exposed to marine splash zones.
\end{abstract}

KEY WORDS: Marine splash zone; Low-carbon steel; Corrosion behavior; Electrochemical impedance spectroscopy (EIS); Wetting degree

\section{Introduction}

The corrosive marine environments are usually divided into atmospheric, splash, tidal, immersion and mud zones. For unprotected steel structures, corrosion is very severe in marine splash zones. Many impact factors, such as the kind of supply of oxygen, wave slamming and salt spray, may cause or accelerate the metal corrosion. However, the most important factor is the dry-wet alternation [1-3]. When the tide ebbs, the steel structures located in splash zone are

Available online at http://link.springer.com/journal/40195

Min Du

ssdm99@ouc.edu.cn

$1 \quad$ Key Laboratory of Marine Chemistry Theory and Technology, Ministry of Education, College of Chemistry and Chemical Engineering, Ocean University of China, Qingdao 266100, China wetted by thin liquid films. With an increase in the exposure time and of the evaporation of seawater, the residual thickness of the seawater films on the metal surface gradually decreases, while the seawater salinity increases. At this point, the steel structures are in the drying stage. At high tide, the steel structures are submerged by seawater again, which is just like the situation of the immersion zones. So, serious corrosion may occur on the steel structures without any protection or if the protection is insufficient [4-7]. Many studies have shown that temperature, wet-dry conditions and relative humidity affect the corrosion and hydrogen permeation behavior of steels in marine splash zones [8-10].

The cathodic protection (CP) is widely considered as a good strategy to prevent the metal corrosion. The theoretical basis of CP is to apply a cathodic current to the steel structures. However, for structures in marine splash zones the cathodic protection has a limited effect. The most important parameters in the cathodic protection for 
structure exposed to marine tidal zones are the penetration depth of the protection current and its magnitude. Moreover, the protective effect of $\mathrm{CP}$ is directly influenced by the medium conductivity $[11,12]$. When being exposed to the air, a thin liquid film will remain on the surface and its thickness decreases gradually with time. So the cross-sectional area of the thin liquid film decreases gradually and the resistance increases significantly. When the liquid film thickness approaches 0 , the protective potential applied by the cathodic protection is almost entirely consumed by the solution resistance, which will lead the cathodic protection current not to reach the surface of the steel structures, similar to that in marine tidal zones [13, 14] and in soil environments [15]. With an increase in the corrosion time, a rust layer forms on the steel surface. The growth of the rust layer under dry-wet alternate environments has been widely studied. The porous and heterogeneous rust layers will affect the persistence time of seawater on the sample surface. Therefore, the corrosion rate and the corrosion processes are influenced by the rust layer [16, 17]. Moreover, the rust layer is very complex because it is composed of several oxides and hydroxides. Different iron oxides and hydroxides are insulators in dry conditions, but become electrical conductive when the seawater seeps into the rust layer. Furthermore, the electrical conductivity of the various components of the rust layer is different. Magnetite $\left(\mathrm{Fe}_{3} \mathrm{O}_{4}\right)$ is an electrical conductor with good compactness and stability, while $\alpha-\mathrm{FeOOH}$ (goethite) is an insulator without electrochemical activity and $\beta$-FeOOH (akaganeite) is a semiconductor. In dry-wet conditions, the content of each substance in the rust layer is constantly changing with the increase in the corrosion time [18, 19]. So, there must be a feedback effect on the cathodic protection applied to the metal due to the electronic conduction of the rust layer. The growth of the rust layer is closely correlated with the frequency of dry-wet alternation. Conversely, through its mass transport properties and porosity, the rust layer has a feedback effect on the environment, such as to extend the time of wetness, which affects the duration of the electrochemical process. Therefore, it is extremely important to study the corrosion process of steel structures in splash zones. To elucidate the corrosion mechanism will be useful to provide effective protection methods.

In order to find out the reasons of the corrosion severity in dry-wet alternation, many researches have been carried out so far [20-23]. The corrosion products of carbon steels exposed to splash zones were analyzed. The results showed that the rust is relatively loose; there are many gaps and cracks in the rust layer, which hinder the formation of protective rust layers. Dry-wet alternation is the external factor that causes serious corrosion of carbon steels. The internal factor is the special function of the rust layer.
Actually, previous researches have shown that the corrosion process of steels in dry-wet alternation conditions could be split into two stages. During the first stage (wet state), the anodic process is the dissolution of iron, which is balanced by the reduction of iron hydroxide in the rust layer [24-28], as shown by Eq. (1). During the second stage (dry state), the main cathodic process is the reduction of oxygen, as widely accepted.

$\mathrm{Fe}^{3+}+8 \mathrm{FeOOH}+3 \mathrm{e} \rightarrow 3 \mathrm{Fe}_{3} \mathrm{O}_{4}+4 \mathrm{H}_{2} \mathrm{O}$.

The purpose of this article is to study the composition/ structure/morphology and corrosion mechanism of Q235 lowcarbon steel in simulated marine tidal zones and to reveal the relationship between the growth process of the rust layer and the humidity of the environment. Besides that, it aims to clarify the effects of the loose rust layer on the microstructure, electric field and electric double layer structure. This study is expected to provide some fundamental knowledge for appropriate corrosion protection in marine tidal zones in the future.

\section{Experimental}

\subsection{Materials and Simulated Experimental Devices}

The experimental material was the Q235 steel, with the chemical composition (wt\%): 0.2 C-0.036 S-0.017 P-0.58 $\mathrm{Mn}-0.21 \mathrm{Cu}$, and balance $\mathrm{Fe}$. The size of specimens for surface and electrochemical analysis was $10 \mathrm{~mm} \times$ $10 \mathrm{~mm} \times 3 \mathrm{~mm}$. The back side of each coupon was welded with copper wire for electric connection in the electrochemical experiments, while a square $(10 \mathrm{~mm} \times 10 \mathrm{~mm})$ surface was exposed. The remaining fraction of the coupon surface was sealed with epoxy resin. Prior to the experiment, the specimen surface was polished with 400\#, 600\#, 800\# $\mathrm{SiC}$ sandpapers step by step and then cleaned with deionized water, degreased with acetone and dried in a cold air stream. At last, the coupons were stored in the dryer for standby.

Compared with the field experiments, the simulation experiments in laboratory can provide better operability and easier coupon recycling. It is more important that the simulation of dry-wet alternation can accurately correspond to the actual environment. The container used to perform the simulation experiments was a plastic cylinder, with an inner diameter of $70 \mathrm{~cm}$ and a height of $120 \mathrm{~cm}$. Testing coupons were fixed in an insulating plastic frame in a trough, and a sprinkler tip was installed above the frame to spray seawater onto the coupons. A microcomputer space-time switch was used to control the work time of the pump $(6 \mathrm{~h})$, and the flow rate was controlled by a rotameter. In addition, an SHT10 sensor was used to monitor the environmental relative humidity and 
temperature changes. The experimental medium was natural seawater, taken from Qingdao. The $\mathrm{pH}$ was 8.1, salinity was 32 and the conductivity was $4 \mathrm{~S} / \mathrm{m}$. After each test cycle, the coupons were retrieved for the following surface analyses and electrochemical measurements.

\subsection{Methods}

\subsubsection{Surface Analysis}

The previous research has shown that iron hydroxide participates in the cathodic reduction reaction. Therefore, in order to prevent the oxidation of the $\mathrm{Fe}$ (II), it is important to preserve the samples before the surface test. The samples were stored in the refrigerator to keep them cold, which is helpful to separate the rust layers. Besides that, the rusted samples were immediately placed on the sample holder and coated with glycerol, to limit the oxidation of the $\mathrm{Fe}(\mathrm{II})$ compounds during the analysis.

The morphology and elemental composition analysis of the corrosion films grown on the Q235 steel were established by scanning electron microscopy (SEM) and energydispersive spectrometry EDS.

The components of the corrosion films were analyzed by Raman spectroscopy.

X-ray photoelectron spectroscopy (XPS) was carried out to further understand the phase composition and structure of the corrosion products at various depths of the rust layer.

\subsubsection{Electrochemical Measurements}

Electrochemical impedance methods are applied in small increments by treating the system with a sinusoidal AC signal disturbance: In this way it is possible to observe the results of the feedback of the disturbance of the system in the steady state. This procedure does not interrupt the polarization process and the test online of the electrode polarization resistance and the differential capacitance on the surface. These methods are widely used in corrosion and electrochemical basic research because they are simple, fast, do not damage the samples and give a large amount of information.

These tests can provide the electrochemical dynamic information, which can reflect the charge and discharge processes of the electric double layer, the charge transfer steps and the mass transfer processes. When the corrosion of the steel structure begins, the corrosion products will cover the metal surface, which will change the electrochemical reaction parameters at the metal/seawater interface, such as the resistance and the electric double layer capacitance. Electrochemical impedance spectroscopy (EIS) measurements were taken by a three-electrode system, consisting of a corroded steel sample as the working electrode, a platinum electrode as the counter-electrode and a saturated calomel electrode (SCE) as the reference electrode. They were symmetrically distributed and connected to each other. The EIS results were obtained by applying an $\mathrm{AC}$ voltage of $10 \mathrm{mV}$ amplitude over the frequency range of $10^{-2}-10^{5} \mathrm{~Hz}$ on an IM6E electrochemical workstation (Germany, Zahner Company). The measured EIS data were fitted by ZView software. Three parallel samples were tested in each condition to ensure the reproducibility, and the most representative experimental results were selected.

\subsubsection{Wetting Characteristics on the Surface of the Sample in Marine Splash Zone}

The wetting degree of the steel specimens in the splash zone is closely related to the splash movement. The wettability of the steel surface in the splash zone can be calculated through the relationship between the wetting degree and the conductivity [29]. The circuit diagram presented in Fig. 1 was designed to obtain the wettability of the steel surface [29]. First, a data acquisition equipment (National Instruments USB 6210) was used to record the voltage change of the external resistor. So, the impedance of the sample could be calculated according to the external resistor and power supply force $E$, and then, the impedance could be converted to admittance. The greater the wetting was, the bigger the admittance. When the sample surface was completely dry, the admittance was 0 . When the specimen surface was wetted completely, the admittance was thought to be $100 \%\left(Y_{0}\right)$. The relationship between wettability, $D_{\mathrm{w}}$, and the admittance, $Y$, is given by

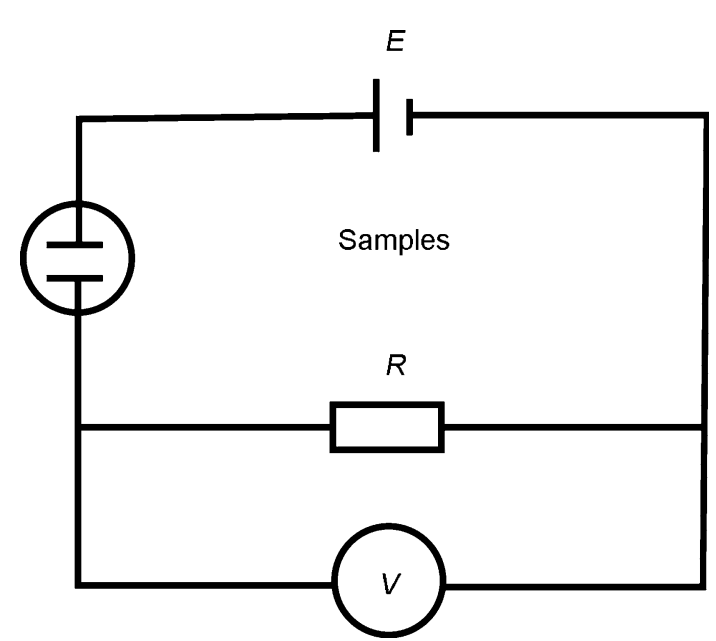

Fig. 1 Circuit diagram for testing the wetting conditions of steel samples exposed to a splash zone 


$$
D_{\mathrm{w}}=\frac{Y}{Y_{0}} \times 100 \%
$$

\section{Results and Discussion}

\subsection{Morphology and Composition of Rust}

The morphology of the corrosion product films formed on the Q235 exposed for different time in the splash zone is shown in Fig. 2. The film seemed to be composed of two layers. The outer layer was yellow and loose, while the inner layer was uniform and compact with a dark gray color. On the surface of the rust layer, there was some white sediment, which might be the seawater salt precipitated when the tide ebbed.

As shown in Fig. 2, when the experiment period was of $15 \mathrm{~d}$, there was no clear difference in micro-corrosion morphologies between the inner layer and the outer layer. They both were scaly. The possible reason is that those
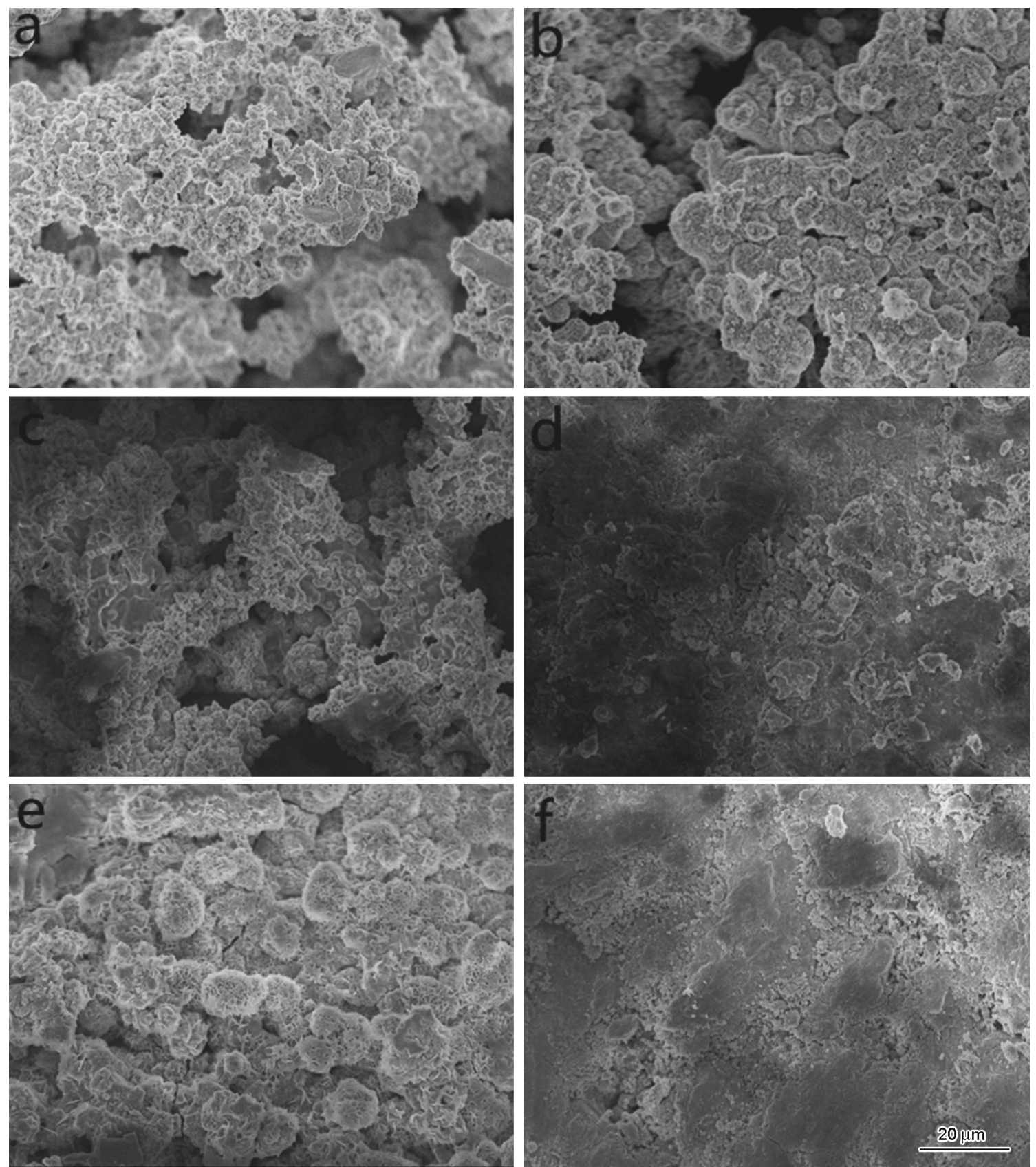

Fig. 2 Micro-corrosion morphologies of Q235 steel after different times of exposure to a splash zone: a 15-d outer layer; b 15-d inner layer; c 30-d outer layer; d 30-d inner layer; e 45-d outer layer; f 45-d inner layer 
corrosion products did not stratify or that separation was not complete by this time. After $30 \mathrm{~d}$, the outside film of the specimens was loose, porous and fell off easily from the substrate. By contrast, the inner corrosion products appearing to be black were distributed uniformly, dense and adhered firmly to the substrate. After $45 \mathrm{~d}$, the microcorrosion morphologies of the outer layer had the shape of cotton wool and contained small holes. The inner rust layer consisted of uniformly distributed flaky crystal was thicker and more compact. With time, both rust layers were becoming compact, implying a corrosion protective effect for the steel. The metal surface appeared to be uneven after removing the corrosion products. It should be noted that localized corrosion had occurred on the specimens.

The composition (at. \%) of the inner and outer rust layers grown on samples corroded in the splash zone after $30 \mathrm{~d}$ obtained by EDS analysis are listed in Table 1 .

The results indicate that $\mathrm{Fe}$ and $\mathrm{O}$ were the elements most enriched in the corrosion products, both in the outer and in the inner layers. Other elements, such as $\mathrm{Mg}, \mathrm{Ca}, \mathrm{Cl}$ and $\mathrm{Na}$, were relatively less enriched.

In order to better understand the composition of the corrosion product films, Raman analysis and XPS were also performed. The results are shown in Figs. 3 and 4, respectively.

The Raman spectrum of the corrosion product films grown on the Q235 steel exposed to a simulated marine splash zone for $10 \mathrm{~d}$ is presented in Fig. 3a. Both the inner and the outer rust layers were made of $\beta-\mathrm{FeOOH}$ (akaganeite) and $\gamma$-FeOOH (lepidocrocite), implying that there was no evident stratification after exposing the samples to the splash zone for $10 \mathrm{~d}$, in agreement with the SEM results. After $30 \mathrm{~d}$, the corrosion products were mainly composed of magnetite $\left(\mathrm{Fe}_{3} \mathrm{O}_{4}\right)$ and $\mathrm{Fe}(\mathrm{III})$ oxyhydroxides, such as $\alpha-\mathrm{FeOOH}$ (goethite), $\beta$-FeOOH (akaganeite) and $\gamma$ $\mathrm{FeOOH}$ (lepidocrocite). Figure $3 \mathrm{~b}$ illustrates the results obtained from the outer layer and the inner layer. For the outer rust layer, the presence of $\mathrm{Fe}_{3} \mathrm{O}_{4}$ (main peaks at 315, 524,670 and $1322 \mathrm{~cm}^{-1}$ ) and $\alpha-\mathrm{FeOOH}$ (peaks at 485 and $303 \mathrm{~cm}^{-1}$ ) was identified by the Raman measurement, in agreement with the X-ray diffraction (XRD) results (not shown in this paper). Besides that, the peaks at 250, 380, 1057 and $1307 \mathrm{~cm}^{-1}$ in the Raman spectrum were assigned to $\gamma$-FeOOH. Conversely, according to the XRD pattern, $\beta$ $\mathrm{FeOOH}$ exists in the outer layer, possibly because the

Table 1 Composition (at. \%) of the rust grown on the Q235 steel after 30-d exposure to a simulated marine splash zone

\begin{tabular}{llrrrrr}
\hline & $\mathrm{O}$ & \multicolumn{1}{c}{$\mathrm{Fe}$} & $\mathrm{Cl}$ & $\mathrm{Mg}$ & $\mathrm{Ca}$ & $\mathrm{Na}$ \\
\hline Outer layer & 43.87 & 9.91 & 10.04 & 2.66 & 0.63 & 9.93 \\
Inner layer & 44.46 & 21.39 & 0.59 & 0.48 & 0.13 & 1.20 \\
\hline
\end{tabular}

various forms of the $\mathrm{Fe}(\mathrm{III})$ oxyhydroxides are not stable and can transform into each other. As shown by the intensity of peaks, in the outer layer of the corrosion product the $\mathrm{Fe}$ (III) oxyhydroxides were the main components, while the content of magnetite was lower.

After removing the outer layers of corrosion products, some characteristic peaks indicated the presence of $\mathrm{Fe}_{3} \mathrm{O}_{4}$ and $\gamma$-FeOOH. Raman spectra showed that $\alpha-\mathrm{Fe}_{2} \mathrm{O}_{3}$ (peaks at 225,245 and $615 \mathrm{~cm}^{-1}$ ) was also present besides $\mathrm{Fe}_{3} \mathrm{O}_{4}$ and $\gamma-\mathrm{FeOOH}$, possibly because there was only a small amount of $\alpha-\mathrm{Fe}_{2} \mathrm{O}_{3}$ in some zones. Compared to the outer layer, magnetite $\left(\mathrm{Fe}_{3} \mathrm{O}_{4}\right)$ was the main corrosion product in the inner layer. This could be because the Fe(III) oxyhydroxides generated in the early stage of the corrosion process could be converted to magnetite, for example according to reaction (1).

The high-resolution XPS spectra of Fe $2 p$ and O $1 s$ are shown in Fig. 4. In the outer layer, the peaks located at $\sim 711.65$ and $\sim 724.49 \mathrm{eV}$ were attributed to $\mathrm{Fe} 2 p_{3 / 2}$ and Fe $2 p_{1 / 2}$, respectively. The distance between the two peaks was about $12.84 \mathrm{eV}$. The binding energy of $\sim 531.43 \mathrm{eV}$ corresponded to $\mathrm{O} 1 s$. In the inner layer, $\mathrm{Fe} 2 p_{3 / 2}, \mathrm{Fe} 2 p_{1 / 2}$ and $\mathrm{O} 1 s$ were located at $\sim 710.37,723.71$ and $\sim 531.00 \mathrm{eV}$, respectively. The distance between two peaks $\left(\mathrm{Fe} 2 p_{3 / 2}\right.$ and $\mathrm{Fe} 2 p_{1 / 2}$ ) was $13.30 \mathrm{eV}$. There was a small deviation for each element's binding energy. This is because that for the same element, the binding energy will be different in different compounds. The theoretical binding energies of $\mathrm{O} 1 s$ and $\mathrm{Fe} 2 p$ of the different iron oxides are listed in Table 2 . These results strongly demonstrate the existence of $\mathrm{FeOOH}$ in the outer layer, while $\mathrm{Fe}_{3} \mathrm{O}_{4}$ was the main corrosion product in the inner layer, in good agreement with the Raman findings.

\subsection{Electrochemical Impedance Spectroscopy Analysis}

The electrochemical impedance spectra are presented in the forms of Nyquist plot in Fig. 5. Figure 6 shows the equivalent circuit model, which was widely used for filmed samples in marine splash zone $[30,31]$. Because of the roughness and porosity on the surface, the process of charging and discharging was not uniform. So, a constantphase element (CPE) was used to replace an ideal capacitance element.

As shown in Fig. 5, it is clear that there is only a single time constant existing in the EIS curve for the steel without exposing to the seawater. The impedance diagram curve was not a perfect semicircle, which may be attributed to a frequency dispersion. This is considered as a capacitive semicircle. The electrochemical equivalent circuit shown in Fig. 6a was used to fit the experimental impedance data. In addition to the case of the samples exposed for $10 \mathrm{~d}$, all 

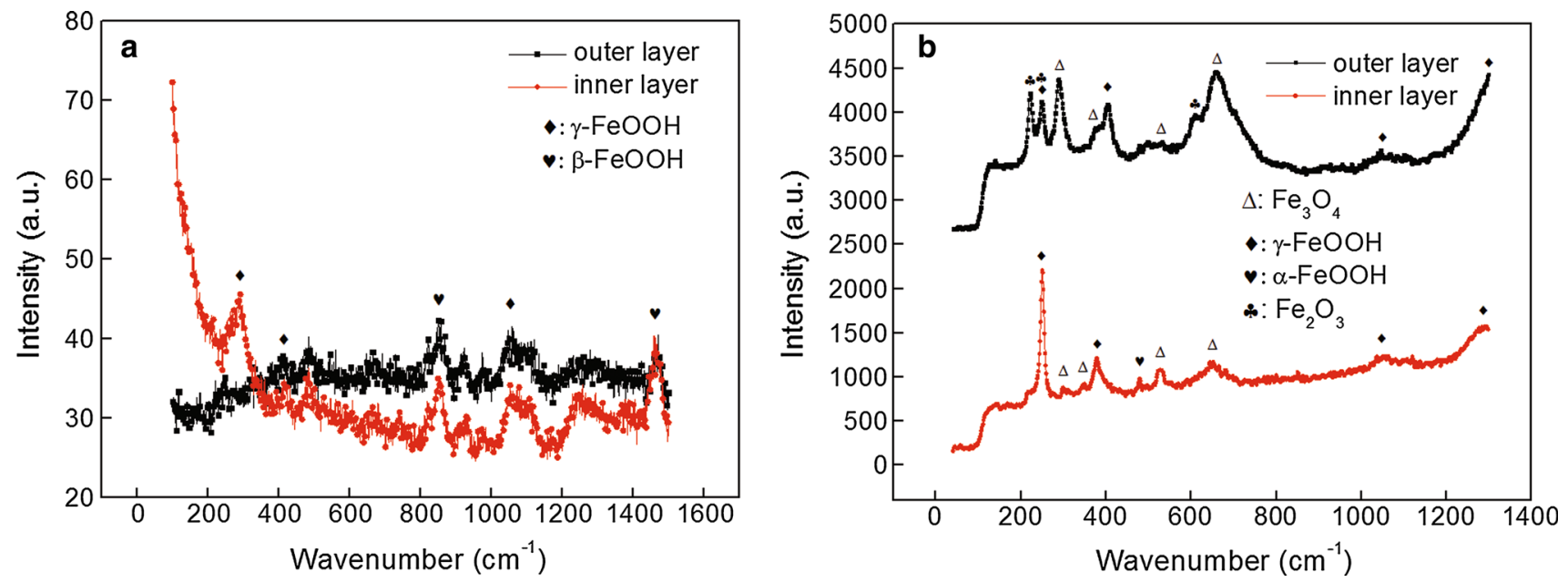

Fig. 3 Raman spectra of the corrosion product films grown on the Q235 steel exposed to a marine splash zone: a 10-d outer and inner layer; b $30-d$ outer and inner layer
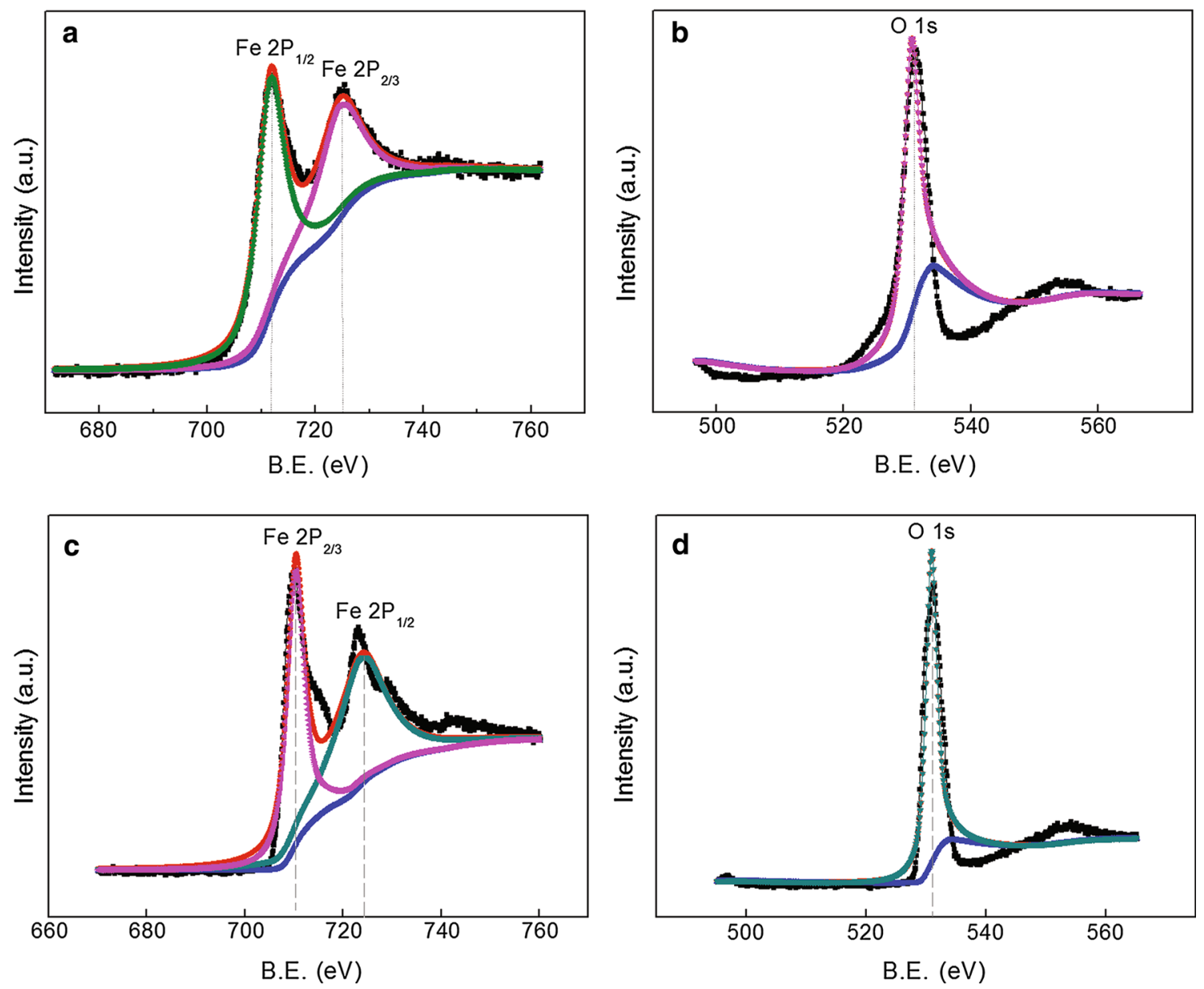

Fig. 4 XPS spectra of Fe $2 p$ and O $1 s$ for the surface of the corrosion product film formed on the Q235 carbon steel exposed to a simulated marine splash zone for $30 \mathrm{~d}$ : a outer layer of $\mathrm{Fe}$; $\mathbf{b}$ outer layer of $\mathrm{O}$; $\mathbf{c}$ inner layer of $\mathrm{Fe}$; $\mathbf{d}$ inner layer of $\mathrm{O}$

the Nyquist plots showed two partial semicircles. After $10 \mathrm{~d}$ of exposure, the Warburg impedance became more and more evident. In this condition, the electrochemical equivalent circuit shown in Fig. $6 \mathrm{~b}$ was used to fit the measured impedance. The fitting results of the EIS plots by Zview software are listed in Table 3. The changes of 
Table 2 Measured and theoretical B.E. of O $1 s$ and Fe $2 p$ of the corrosion product film formed on the Q235 carbon steel exposed to a simulated marine splash zone after $30 \mathrm{~d}$

\begin{tabular}{llll}
\hline Compound & Measured B.E. (V) & Theoretical B.E. (V) & Deviation B.E. (V) \\
\hline $\mathrm{Fe}_{3} \mathrm{O}_{4}\left(\mathrm{Fe} \mathrm{2} p_{1 / 2}\right)$ & 723.71 & 723.50 & 0.21 \\
$\mathrm{Fe}_{3} \mathrm{O}_{4}\left(\mathrm{Fe} \mathrm{2} p_{2 / 3}\right)$ & 710.37 & 710.20 & 0.17 \\
$\mathrm{Fe}_{3} \mathrm{O}_{4}(\mathrm{O} 1 s)$ & 531 & 529.80 & 0.30 \\
$\mathrm{FeOOH}\left(\mathrm{Fe} 2 p_{1 / 2}\right)$ & 724.49 & 724.30 & 0.19 \\
$\mathrm{FeOOH}\left(\mathrm{Fe} 2 p_{2 / 3}\right)$ & 711.65 & 711.50 & 0.15 \\
$\mathrm{FeOOH}(\mathrm{O} 1 s)$ & 531.43 & 531.70 & 0.27 \\
\hline
\end{tabular}

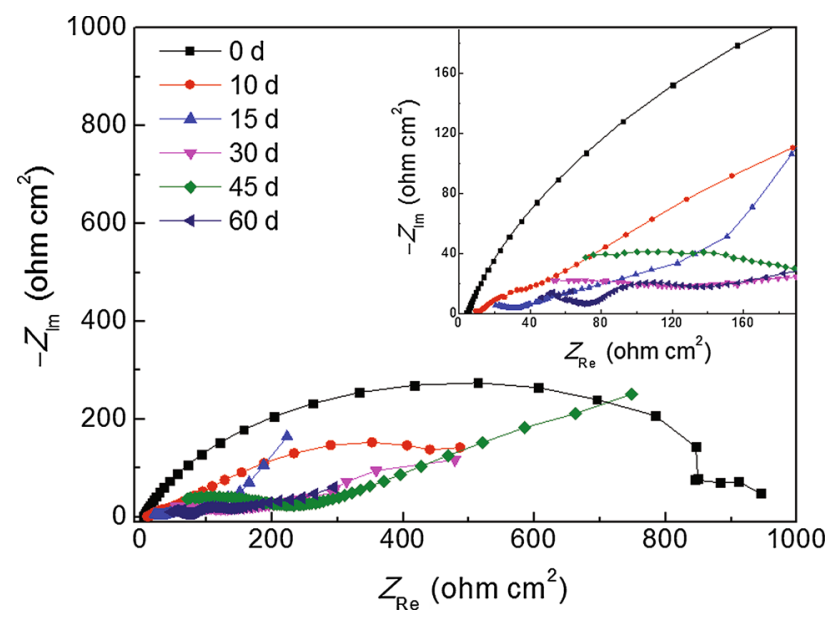

Fig. 5 Nyquist plot of Q235 samples exposed to a marine splash zone in different test cycles

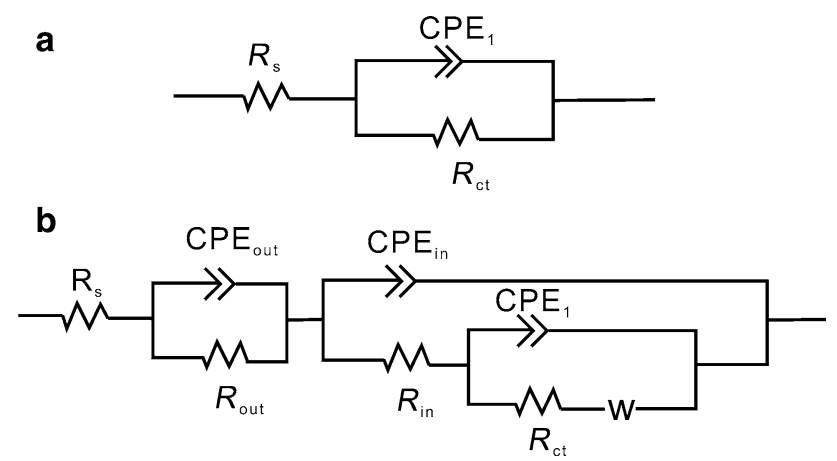

Fig. 6 Equivalent circuit for Q235 samples exposed to a simulated marine splash zone. $R_{\mathrm{S}}$ resistance of solution; $\mathrm{CPE}_{\text {out }}, \mathrm{CPE}_{\text {in }}$ capacitance of the outer and inner rust layer; $R_{\text {out }}, R_{\text {in }}$ resistance of the outer and inner rust layer

resistance and capacitance for the inner and outer rust layers with time are shown in Fig. 7.

According to the theoretical formula, $C$ is given by the equation: $C=\varepsilon \varepsilon_{0} A / d, R=\rho d / A$, where $A$ and $d$ represent the effective area and thickness of the rust layer, respectively; $\varepsilon_{0}$ is the vacuum dielectric constant, $8.85 \times 10^{-14} \mathrm{~F} /$ $\mathrm{cm}$, while $\varepsilon$ and $\rho$ represent the dielectric constant and resistivity of the rust layer, respectively. Clearly, the magnitude of the capacitance and resistance is closely related to the thickness of the rust layer. As shown in Fig. $7 \mathrm{~b}, C_{\text {in }}$ increases at first and then decreases rapidly ( $30 \mathrm{~d}$ ), indicating that the inner rust layer was thin at first and then thickened. A comparison of Fig. 7a, b shows that when $C_{\text {in }}$ increases, $C_{\text {out }}$ decreases correspondingly. This change indicates that the inner rust layer was continuously converted into the outer rust layer; furthermore, the thickness of the inner rust layer itself was also increased with time. According to the theoretical formula, the changes of the resistance and capacitance should have opposite trend. Figure 7 shows that the variations of $R_{\text {in }}\left(R_{\text {out }}\right)$ and $C_{\text {in }}\left(C_{\text {out }}\right)$ are basically the same, even if sometimes the changes are not quite consistent. This may be related to the morphology and the uniformity of the rust layer. In early corrosion stage, the porosity is very large. When the capacity of absorbing water increases, the resistance and capacitance decrease at the same time. Besides that, as mentioned earlier, the electrical conductivity of the different components of the rust layer is different. As the corrosion time increases, the content of $\mathrm{Fe}_{3} \mathrm{O}_{4}$ increases accordingly, leading to stronger conductivity, giving a further explanation of the decreasing trend of the inner rust layer resistance. For $R_{\text {out }}$, the results of the $\mathrm{XRD}$ measurements indicate the presence of large amounts of insulators and semiconductors in the outer rust layer. Therefore, the resistance of the outer rust layer is increased with time.

It is generally accepted that the modulus values of the high-frequency impedance in the Bode diagrams represent the sum of the $R_{\mathrm{r}}$ (rust resistance) and $R_{\mathrm{S}}$ (solution resistance). $R_{\mathrm{r}}$ mainly reflects some characteristics of the rust layer, like porosity, continuity and the adhesion with the matrix. In order to avoid interference of high-frequency phase shift, an average impedance near $1188.5 \mathrm{~Hz}$ was selected as the rust layer impedance. The changes of the rust layer impedance over time are shown in Fig. 8. The rust layer impedance shows an increasing trend with time, which suggests that the rust layer was becoming increasingly dense. 
Table 3 Impedance parameters of Q235 after different exposure times

\begin{tabular}{|c|c|c|c|c|c|c|}
\hline $\begin{array}{l}t \\
\text { (d) }\end{array}$ & $\begin{array}{l}R_{\mathrm{s}} \\
\left.(\mathrm{ohm} \mathrm{cm})^{2}\right)\end{array}$ & $\begin{array}{l}\mathrm{CPE}_{\text {out }}(n) \\
\left(\mathrm{mF} \mathrm{cm}{ }^{-2}\right)\end{array}$ & $\begin{array}{l}R_{\text {out }} \\
\left(\text { ohm cm }{ }^{2}\right)\end{array}$ & $\begin{array}{l}\mathrm{CPE}_{\text {in }}(n) \\
\left(\mathrm{mF} \mathrm{cm}^{-2}\right)\end{array}$ & $\begin{array}{l}R_{\text {in }} \\
\left.(\mathrm{ohm} \mathrm{cm})^{2}\right)\end{array}$ & $\begin{array}{l}R_{\mathrm{ct}} \\
\left.(\mathrm{ohm} \mathrm{cm})^{2}\right)\end{array}$ \\
\hline 10 & 5.73 & $0.096(0.54)$ & 6.27 & $0.80(0.66)$ & 42.5 & 589 \\
\hline 15 & 6.11 & $0.026(0.53)$ & 24.74 & $1.1(0.15)$ & 18.7 & 44.8 \\
\hline 30 & 6.88 & $0.0042(0.69)$ & 46.84 & $1.05(0.61)$ & 28.6 & 309 \\
\hline 45 & 6.33 & $0.039(0.45)$ & 33.06 & $0.63(0.68)$ & 57.7 & 55.7 \\
\hline 60 & 6.25 & $0.049(0.40)$ & 72.14 & $0.048(0.74)$ & 55.7 & 230 \\
\hline
\end{tabular}
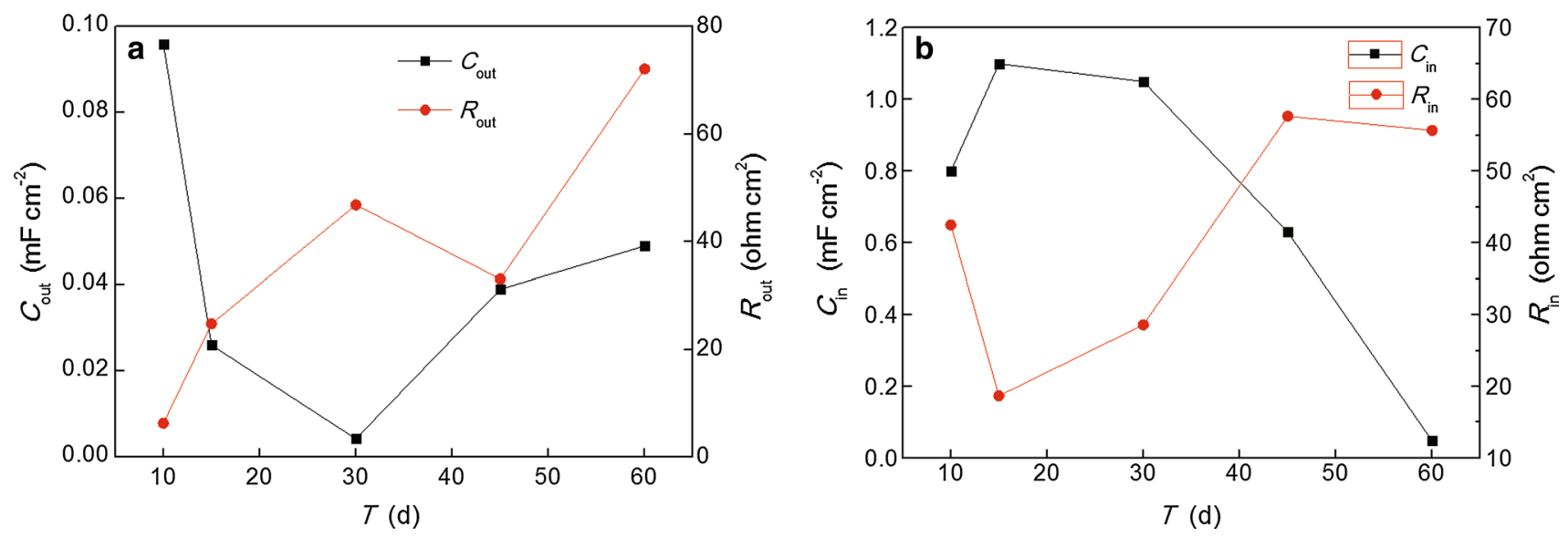

Fig. 7 Changes with time of resistance and capacitance for the inner and outer rust layer grown in a simulated marine splash zone: a outer layer; b inner layer

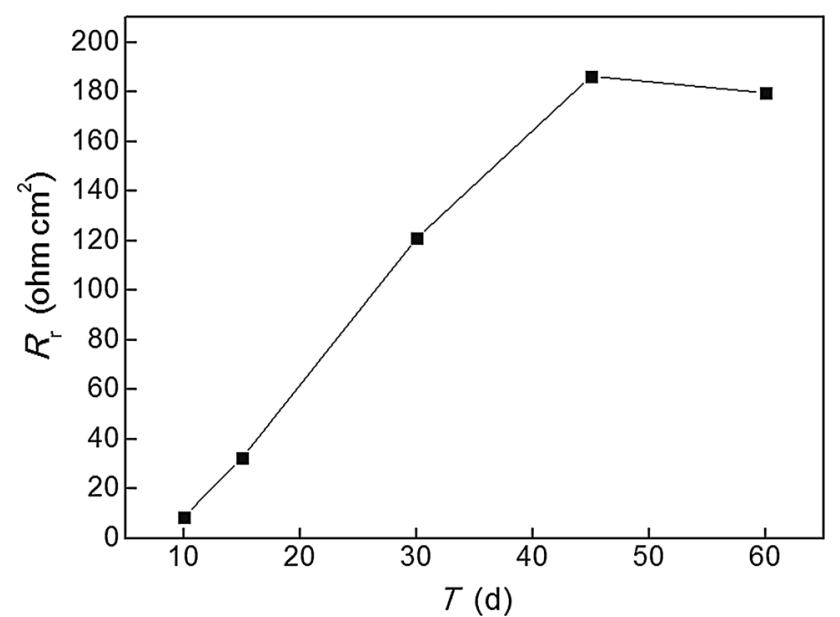

Fig. 8 Change of $R_{\mathrm{r}}$ with time

\subsection{Surface Wetting Characteristics of Samples in the Marine Splash Zone}

Wettability changes on steel surface were determined based on the circuit diagram shown in Fig. 1. The changes of the wetting degree of the steel surface during the drying process were measured, as shown in Fig. 9. It can be seen

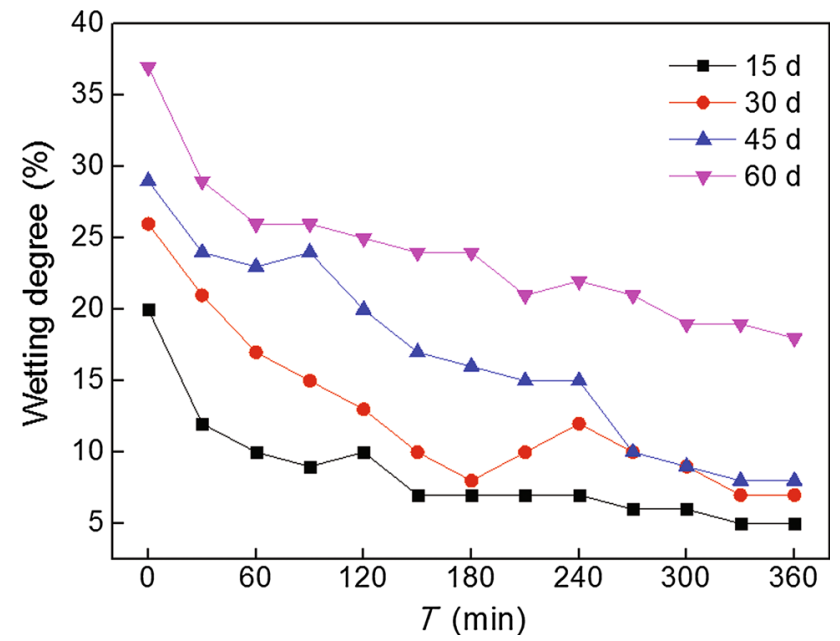

Fig. 9 Changes of the wetting degree of the rusted steel surface during a drying process of $6 \mathrm{~h}$

that the longer is the exposure time, the better is the wetting degree. This is because the rust formed on the metal surface in the corrosion process has the ability to absorb water. When the thickness increases, the ability of water absorption increases. Therefore, in cathodic protection systems, some materials with the ability to absorb water 
could be used to maintain a good wettability, so to guarantee the cathodic protection effectiveness.

\section{Conclusions}

(1) The rust grown in a marine splash zone consisted of outer and inner rust layers. The products of the outer rust layer were mainly made up of $\mathrm{Fe}(\mathrm{III})$ oxyhydroxide $(\mathrm{FeOOH})$, while the main component of the inner rust layer was magnetite $\left(\mathrm{Fe}_{3} \mathrm{O}_{4}\right)$. In addition, with the extension of corrosion time, both rust layers became denser, thus playing a protective role toward the matrix.

(2) $\mathrm{Fe}(\mathrm{III})$ oxyhydroxides $(\mathrm{FeOOH})$ generated in the early stage of the corrosion process could be converted to magnetite $\left(\mathrm{Fe}_{3} \mathrm{O}_{4}\right)$. The rust participated in the cathodic process.

(3) The corrosion product film had an evident effect on the preservation of seawater during the drying period. Thus, it could improve the cathodic protection effect for structures exposed to marine splash zone.

Acknowledgements This work was supported by the National Science Foundation of China (No. 41576076); the National Environmental Corrosion Platform (NECP); and the National Key Basic Research Program (“973 Program,” No. 2014CB643300).

\section{References}

[1] D.S. Dunn, M.B. Bogart, C.S. Brossia, G.A. Cragnolino, Corrosion 56, 470 (2000)

[2] J.D. Liu, Y.T. Li, B.R. Hou, Mater. Prot. 45, 29 (2012)

[3] E. Schindelholz, R.G. Kelly, Corros. Rev. 30, 135 (2001)

[4] W.M. Zhao, Y. Wang, C. Liu, Surf. Coat. Technol. 205, 2267 (2012)
[5] H.Q. Shao, W.L. Han, X.Y. Wang, A.G. Li, Corros. Prot. 29, 646 (2008)

[6] J.G. Liu, Y.T. Li, B.R. Hou, Corros. Prot. 33, 833 (2012)

[7] Z.G. Xiao, J.A. Zhang, H. Zheng, C.G. Li, Total Corros. Control 26, 23 (2012)

[8] X.M. Yu, Y.L. Huang, A.P. Yadav, W.J. Qu, R. DE Marco, J. Electrochem. Soc. 87, 541 (2015)

[9] X.M. Yu, Y.L. Huang, W.J. Qu, A.P. Yadav, R. DE Marco, Int. J. Electrochem. Sci. 9, 3760 (2014)

[10] G.A. Mahdy, A. Nishikata, T. Tsuru, Corros. Sci. 42, 183 (2000)

[11] R. Montoya, V. Nagel, J.C. Galvan, J.M. Bastidas, Corros. Sci. 51, 2857 (2009)

[12] R. Montoya, V. Nagel, J.C. Galvan, J.M. Bastidas, Mater. Corros. 64, 1055 (2013)

[13] X. Mu, J. Wei, J.H. Dong, W. Ke, Acta Metall. Sin. (Engl. Lett.) 50, 1294 (2014)

[14] J.A. Ieong, C.K. Jin, W.S. Chung, J. Adv. Concr. Technol. 10, 389 (2012)

[15] H.N. Hao, Z.L. Li, T.Y. Wang, Chem. Eng. Mach. 39, 494 (2012)

[16] X. Zhang, S.W. Yang, W.H. Zhang, H. Guo, X.L. He, Corros. Sci. 82, 165 (2014)

[17] T. Ohtsuka, T. Komatsu, Corros. Sci. 47, 2571 (2005)

[18] S. Hœrlé, Corros. Sci. 46, 1431 (2004)

[19] Y. Zou, J. Wang, Y. Zheng, J. Chin. Soc. Corros. Prot. 31, 92 (2011)

[20] X. Mu, J. Wei, J.H. Dong, W. Ke, Acta Metall. Sin. (Engl. Lett.) 48, 420 (2012)

[21] R. Jeffrey, R.E. Melchers, Corrosion 65, 695 (2009)

[22] R. Jeffrey, R.E. Melchers, Corros. Sci. 65, 26 (2012)

[23] P. Refait, Corros. Sci. 90, 375 (2015)

[24] H. Okada, Y. Hosoi, H. Naito, Corrosion 26, 429 (1970)

[25] T. Li, B.R. Hou, Chin. J. Oceanol. Limnol. 16, 231 (1998)

[26] T. Nishimura, H. Katayama, K. Noda, T. Kodama, Corrosion 56, 935 (2000)

[27] J.L. Crolet, N. Thevenot, S. Nesic, Corrosion 54, 194 (1998)

[28] H. Antony, L. Legrand, L. Marechal, S. Perrin, Ph Dillmann, A. Chausse, Electrochim. Acta 51, 745 (2005)

[29] Y.L. Huang, X.M. Yu, H.M. Zheng, W.J. Qu, A.P. Yadav, R.D. Marco, J. Chin. Soc. Corros. Prot. 35, 475 (2015)

[30] W.J. Qu, Y.L. Huang, X.M. Yu, D. Lu, H.M. Zheng, R.D. Marco, Corros. Eng., Sci. Technol. 51, 163 (2016)

[31] J.G. Liu, Z.L. Li, Y.T. Li, B.R. Hou, Anti-Corros. Methods Mater. 63, 56 (2016) 